\title{
ГЕНЕТИКА GENETICS
}

Использование метода Multifactor Dimensionality

И.В. Пономаренко Reduction (MDR) и его модификаций для анализа ген-генных и генно-средовых взаимодействий при генетико-эпидемиологических исследованиях (обзор)

\author{
Федеральное государственное автономное образовательное учреждение \\ высшего образования «Белгородский государственный национальный \\ исследовательский университет» (НИУ «БелГУ»), \\ ул. Победы, д. 85, г. Белгород, 308015, Российская Федерация \\ Автор для переписки: И.В. Пономаренко (ponomarenko_i@bsu.edu.ru)
}

\begin{abstract}
Аннотация
Актуальность: При генетико-эпидемиологическом исследовании мультифакториальных признаков (заболеваний) важной задачей является оценка ген-генных и генно-средовых взаимодействий, ассоциированных с изучаемым фенотипом. Цель исследования: Провести систематический анализ данных, имеющихся в современной литературе, о возможностях метода Multifactor Dimensionality Reduction (MDR) и его различных модификаций (GMDR, MB-MDR) при изучении генгенных и генно-средовых взаимодействий. Материалы и методы: В обзор включены современные данные зарубежных и отечественных статей, найденные в Pubmed по данной теме. Результаты: Метод MDR дает возможность оценивать ген-генные и генно-средовые взаимодействия, ассоциированные с качественными фенотипами с учетом коррекции на качественные ковариаты и проводить их валидацию с помощью пермутационного теста. Так же он позволяет проводить кросс-валидацию моделей, оценивать характер (synergy, additive, redundancy) и силу (доля вклада в энтропию) этих взаимодействий и их визуализировать графически. Данный метод не дает возможность изучать количественные фенотипы и учитывать количественные ковариаты. Метод MB-MDR позволяет анализировать межгенные и генно-средовые взаимодействия, ассоциированные с качественными и количественными фенотипами, учитывать в анализе ковариаты, проводить валидацию полученных моделей с помощью пермутационного теста, а также определять отдельные комбинации факторов, ассоциированные с исследуемыми фенотипами с учетом ковариат и значимости (рисковое или протективное значение). Метод GMDR дает возможность оценивать ген-генные и генно-средовые взаимодействия, ассоциированные с качественными фенотипами с учетом коррекции на качественные и количественные ковариаты, проводить их валидацию с помощью пермутационного теста и визуализировать графически, позволяет проводить кросс-валидацию наиболее значимых моделей с учетом коррекции на ковариаты и множественные сравнения (пермутационный тест). Заключение: При генетикоэпидемиологическом исследовании наиболее оптимальным является использование вначале метода MB-MDR для установления наиболее значимых $\mathrm{SNP} \times \mathrm{SNP}$ и генно-средовых взаимодействий, их валидация с помощью пермутационного те-
\end{abstract}


ста, а также определение конкретных комбинаций, ассоциированных с исследуемым фенотипом. Далее с помощью метода GMDR проведение кросс-валидации наиболее значимых моделей с учетом коррекции на ковариаты и множественные сравнения (пермутационный тест). Затем использование метода MDR для оценки характера (synergy, additive, redundancy) и силы (доля вклада в энтропию) $\mathrm{SNP} \times \mathrm{SNP}$ и генно-средовых взаимодействий и их графической визуализации.

Ключевые слова: полиморфизм; ассоциации; SNP $\times$ SNP взаимодействия; генносредовые взаимодействия; MDR; MB-MDR; GMDR

Информация для цитирования: Пономаренко И.В. Использование метода Multifactor Dimensionality Reduction (MDR) и его модификаций для анализа ген-генных и генно-средовых взаимодействий при генетико-эпидемиологических исследованиях (обзор) // Научные результаты биомедицинских исследований. 2019. Т.5, № 1. C. 4-21 [Ponomarenko IV. Using the method of Multifactor Dimensionality Reduction (MDR) and its modifications for analysis of gene-gene and gene-environment interactions in genetic-epidemiological studies (review). Research Results in Biomedicine. 2019;5(1):4-21 (In Russian)]. DOI: 10.18413/2313-8955-2019-5-1-0-1

Irina V. Ponomarenko

Using the method of Multifactor Dimensionality Reduction (MDR) and its modifications for analysis of gene-gene and gene-environment interactions in genetic-epidemiological studies (review)

\author{
Belgorod State National Research University, \\ 85 Pobedy St., Belgorod, 308015, Russia \\ Corresponding author: Irina V. Ponomarenko (ponomarenko_i@bsu.edu.ru)
}

\begin{abstract}
Background: In the genetic and epidemiological study of multifactorial signs (diseases), an important task is to assess the genetic and genetic-environmental interactions associated with the studied phenotype. The aim of the study: To carry out a systematic analysis of the data available in the modern literature on the possibilities of the method of Multifactor Dimensionality Reduction (MDR) and its various modifications (GMDR, MB-MDR) in the study of gene-gene and gene-environment interactions. Materials and methods: The review includes modern data of foreign and domestic articles on this topic found in Pubmed. Results: The MDR method makes it possible to evaluate genegene and gene-environment interactions associated with qualitative phenotypes, taking into account the correction for qualitative covariates and to carry out their validation using a permutation test. It also allows for cross-validation of models, assessment of the nature (synergy, additive, redundancy) and strength (contribution to entropy) of these interactions and their graphical visualization. This method makes it impossible to study quantitative phenotypes and to take into account quantitative covariates. The MB-MDR method allows to analyze the intergenic and gene-environment interactions associated with qualitative and quantitative phenotypes, to take into account covariates in the analysis, to validate the obtained models using the permutation test, and to determine individual combinations of factors associated with the studied phenotypes, taking into account covariates and significance (risk or protective value). The GMDR method makes it possible to evaluate gene-gene and gene-environment interactions associated with qualitative phenotypes with regard to correction for qualitative and quantitative covariates, to carry out their validation using the permutation test and visualize graphically; it
\end{abstract}


allows for cross-validation of the most significant models, taking into account correction for covariates and multiple comparisons (permutation test). Conclusion: In the genetic-epidemiological study, the most optimal method is to use the MB-MDR method to establish the most significant SNP $\times$ SNP and gene-environment interactions, their validation by means of the permutation test, as well as to determine the specific combinations associated with the phenotype under study. Next, using the GMDR method, crossvalidation of the most significant models, taking into account the correction for covariates and multiple comparisons (permutation test), and, finally, the use of the MDR method to estimate the nature (synergy, additive, redundancy) and strength (contribution to entropy) of SNP $\times$ SNP and gene-environment interactions and their graphical visualization.

Keywords: polymorphism; associations; $\mathrm{SNP} \times \mathrm{SNP}$ interactions; gene-environment interactions; MDR; MB-MDR; GMDR

\section{При генетико-эпидемиологическом} исследовании мультифакториальных признаков важной задачей является оценка генгенных и генно-средовых взаимодействий, ассоциированных с развитием исследуемого фенотипа. Это связано с тем, что наряду с главными эффектами полиморфных локусов значимую роль при формировании мультифакториальных фенотипов (как качественных - например, развитие заболевания, так и количественных, например уровень артериального давления или возраст менархе) имеют ген-генные (эпистатические) взаимодействия и генно-средовые взаимодействия (взаимодействия полиморфных локусов со средовыми факторами риска), вклад которых в развитие сложно наследуемых признаков весьма существенен [1-3]. Существуют различные методы оценки генгенных и генно-средовых взаимодействий, вовлеченных в развитие как качественных, так и количественных признаков (регрессионный анализ, метод монте-карло марковскими цепями, снижения размерности) [4-8].

Одним из методов, позволяющих оценить межгенные взаимодействия, является регрессионная модель анализа взаимодействия генов, реализованная в программном обеспечении gPLINK v2.050 в рамках использования процедуры «epistasis» [4]. Для оценки бивариантного признака (например, «больной-здоровый») используется модель логистической регрессии, предполагающая, что вероятность события (формирование заболевания) описывается как логическая функция от линейной комбинации независимых переменных (факторов-предикторов, в данном случае полиморфных локусов). При анализе количественных фенотипов (уровень артериального давления, возраст менархе, рост, вес тела, индекс массы тела и др.) используется линейная регрессия от факторов-предикторов. При необходимости в регрессионный анализ включаются ковариаты. Следует отметить, что ограничением данного метода является возможность анализа только двух-локусных взаимодействий и отсутствие процедуры валидизации результатов с учетом множественных сравнений. Изучение эпистатических взаимодействий полиморфных локусов с использованием программного обеспечения gPLINK v2.050 посвящены многочисленные работы $[9,10]$.

Другим методом, используемым для решения задачи оценки ген-генных взаимодействий, является метод Монте-Карло Марковскими цепями (Markov Chain Monte Carlo, MCMC), реализованный в программном обеспечении APSampler (http://sources.redhat.com/cygwin). В рамках данной программы осуществляется поиск генетических паттернов (сочетания генетических вариантов различных локусов), ассоциированных с фенотипическим признаком (заболеванием) [5, 6]. Поиск паттернов осуществляется с помощью процедуры МонтеКарло Марковскими цепями, при этом на каждом шаге рассматривается сразу несколько паттернов, а их набор оптимизируется от шага к шагу с точки зрения вероятности того, что все паттерны из набора независимо друг от друга и одновременно ассоциированы с признаком. Вероятность 
ассоциации каждого паттерна оценивается непараметрическим критерием Вилкоксона, при этом сравниваемые подгруппы устроены так, что они отличаются носительством только одного паттерна из набора. В результате этого этапа формируется список паттернов, ассоциированных с развитием заболевания. На следующем этапе происходит валидация этих данных. Для каждого паттерна из списка вычисляется значимость ассоциации по Фишеру. Далее программа несколько раз перемешивает метку фенотипического признака и еще раз запускает поиск ассоциированных паттернов. Достоверности ассоциации по результатам запусков с перемешанным фенотипом дают распределение достоверностей находок при условии нулевой гипотезы, утверждающей отсутствие действительных ассоциаций в начальных данных. Это нулевое распределение используется для валидации сочетаний, найденных на первом этапе [6]. Сила ассоциации оценивается показателем отношения шансов (OR) с 95\% доверительным интервалом $(95 \% \mathrm{CI})$. Коррекция на множественные сравнения проводится с помощью поправки Бонферрони, метода FDR, пермутационного теста. Следует отметить, что ограничением этого метода является невозможность проведения кофакторного анализа, а также он не позволяет изучать генносредовые взаимодействия. Программное обеспечение APSampler и используемый в нем метод Монте-Карло Марковскими цепями (Markov Chain Monte Carlo, MCMC) для решения задач оценки ген-генных взаимодействий активно применяется в исследовательских работах [11-14].

Широкое распространение в генетикоэпидемиологических исследованиях как зарубежных [7, 15-28] так и российских ученых $[29,30]$ в последние годы получает метод снижения размерности - MDR (Multifactor Dimensionality Reduction) и его модификации (GMDR, MB-MDR). Данный метод, дает возможность оценить как ген-генные, так и генно-средовые взаимодействия, ассоциированные с формированием мультифакториального фенотипа. Метод снижения размерности MDR (Multifactor Dimensionality Reduction) позволяет уменьшить размер- ность числа рассчитываемых параметров при одновременной оценке взаимодействий большого количества полиморфизмов за счет конструирования новых переменных на основе суммирования сочетаний генотипов повышенного и пониженного риска формирования заболевания [7, 8, 31].

Метод MDR является непараметрическим [8], он не предполагает какой-то модели наследования признака и поэтому может быть использован для анализа любых фенотипов без априорных предположений. Алгоритм проведения MDR метода представлен следующими этапами. На первом этапе MDR-анализа исходные данные случайным образом делятся на две выборки: обучающую (9/10 данных) и тестовую (1/10 данных). Затем, для каждой комбинации аллелей и генотипов, присутствующей в обучающей выборке, рассчитывается параметр, характеризующий соотношение количества больных и здоровых, несущих эту комбинацию, и в зависимости от величины этого параметра комбинации классифицируются на категории высокого и низкого риска. В результате этого осуществляется переход от $n$-мерного пространства всех единичных полиморфных участков и фенотипа к двумерному пространству, где одно измерение - это уровень риска, а второе - носительство данной комбинации аллелей. Среди всех возможных выделяются комбинации с наименьшей ошибкой классификации в обучающей и тестовой выборках. Следует отметить, что деление на группы осуществляется 10 раз на основе изменяемых каждый раз параметров генератора случайных чисел (рисунок 2). При этом показатель согласованности модели (Cross Validation Consistency - CVC) показывает, сколько раз из этих 10 она идентифицировалась как лучшая. В результате MDR анализа выявляются наилучшие модели для 2n, 3n, 4n и т.д. сочетаний SNP т.е. модели, имеющие наибольший показатель согласованности (CVC) и наименьшую ошибку предсказания (наибольшую точность предсказания модели - Testing Balanced Accuracy). Модель считается валидированной, если ее согласованность 9/10 и более [7, 8, 31]. 
Метод MDR реализован в программHOM обеспечении MDR (http://sourceforge.net/projects/mdr). Коррекция на множественные сравнения в данном случае проводится с помощью пермутационного теста в программном обеспечении MDRpt

(http://sourceforge.net/projects/mdr/files/mdrpt). Следует отметить, что программное обеспечение метода MDR позволяет построить дендрограмму или граф и таким образом визуализировать рассматриваемые генгенные и генно-средовые взаимодействия, а также оценить характер этих взаимодействий (synergy, additive, redundancy) и их силу (доля вклада в энтропию). В работе Москаленко М.И. [32] представлены данные, полученные с использованием метода
MDR при анализе взаимодействия полиморфных локусов матриксных металлопротеиназ (MMP), ассоциированных с развитием гипертонической болезни. На рисунке 1 представлены данные, характеризующие комбинации генотипов повышенного (темно-серые ячейки), пониженного (светлосерые ячейки) и отсутствия (белые ячейки) риска в рамках наиболее значимых моделей межгенных взаимодействий (A, B, C, D обозначение моделей). На рисунке 2 представлены дендрограмма (А) и граф (B) межгенных взаимодействий $M M P$ при формировании эссенциальной гипертензии, демонстрирующие характер этих взаимодействий (synergy, additive, redundancy) и их силу (доля вклада в энтропию).

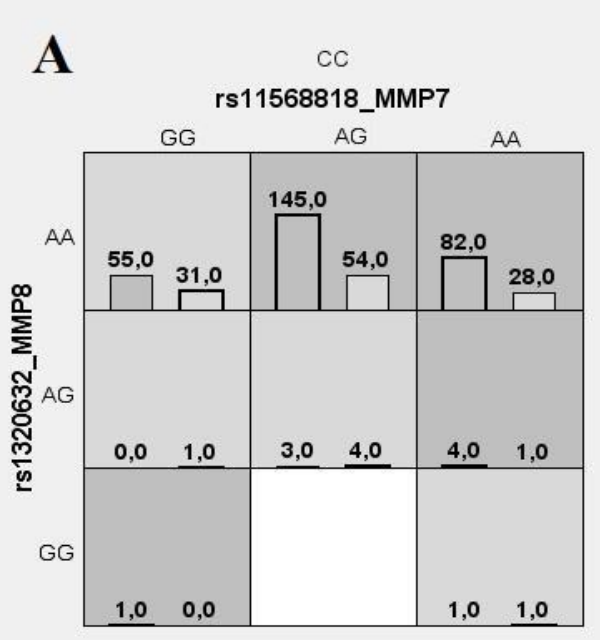

B

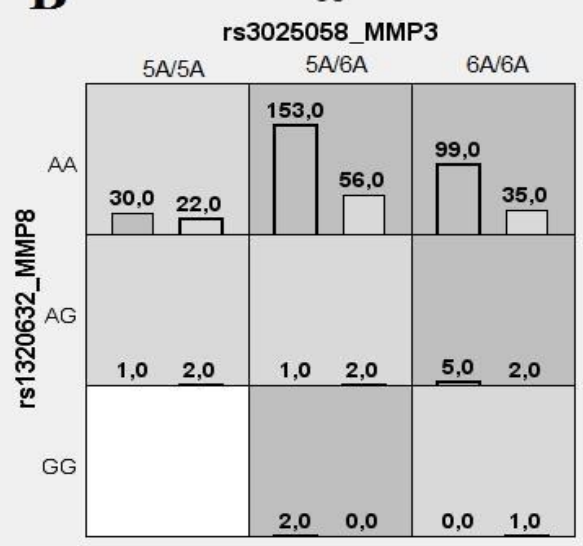

rs11225395_MMP8

CT

rs11568818_MMP7

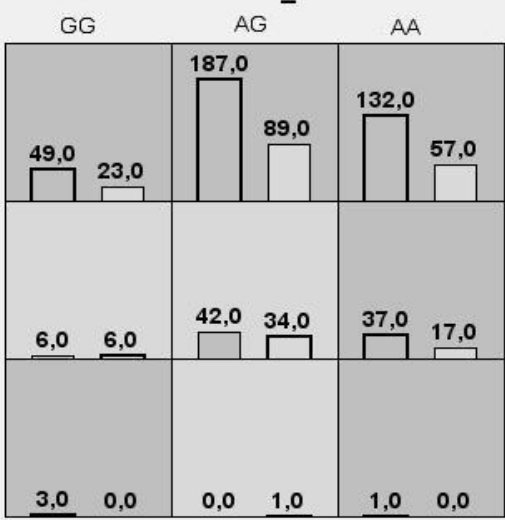

rs11225395_MMP8

CT

rs3025058_MMP3

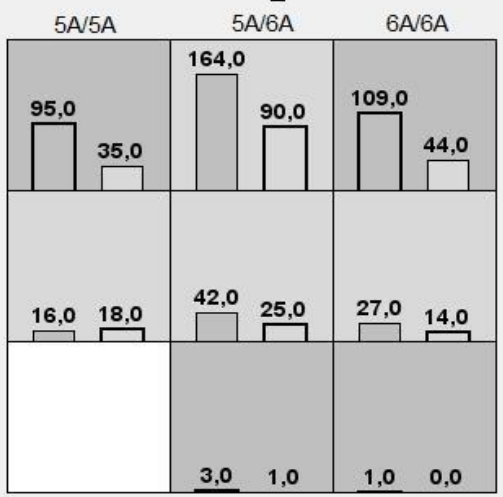

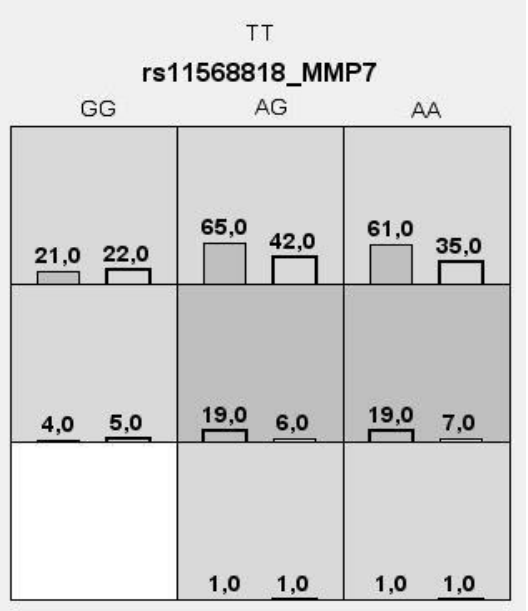

TT

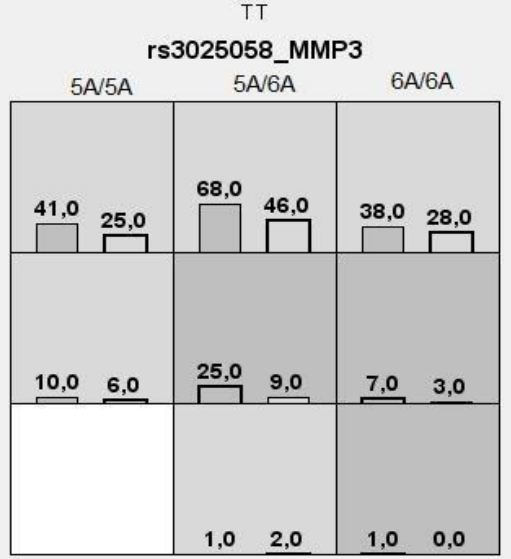



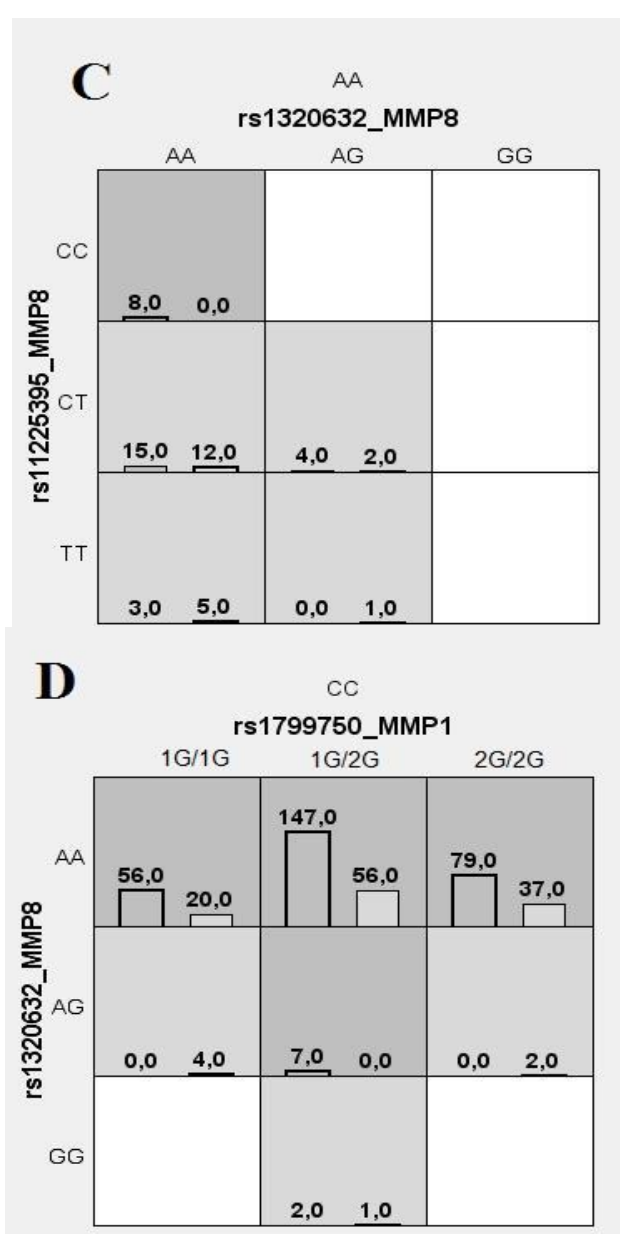

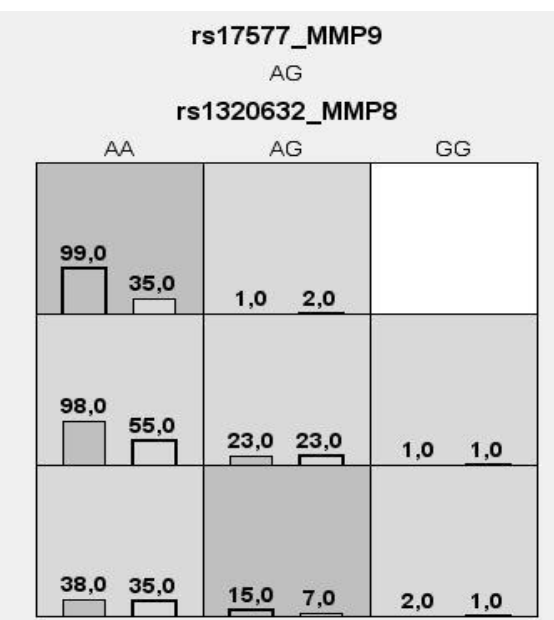

rs11225395_MMP8

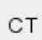

rs1799750_MMP1

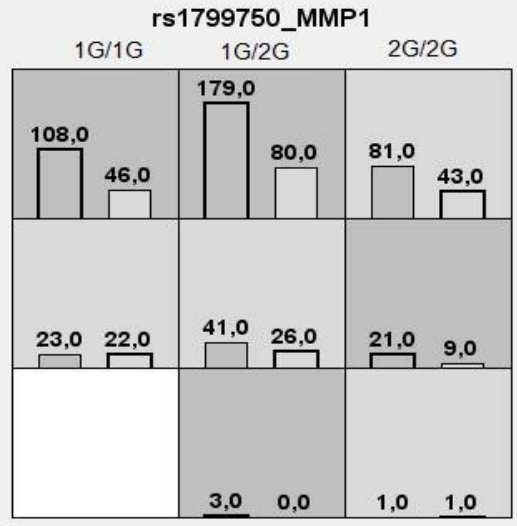

GG

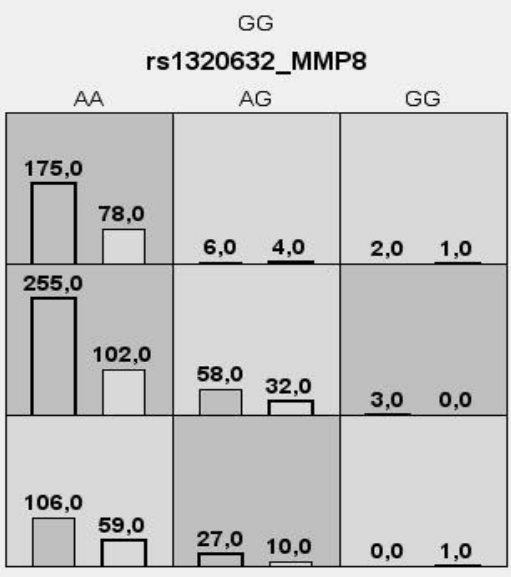

TT

rs1799750_MMP1

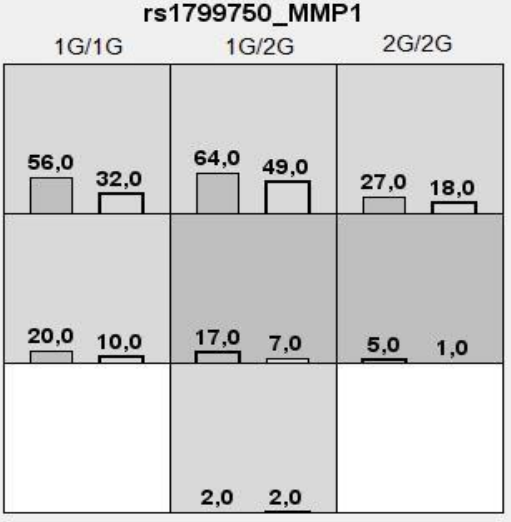

Рис. 1. Диаграмма моделей взаимодействий полиморфных локусов $M M P$ при формировании эссенциальной гипертензии (ЭГ)

Примечание: получено методом MDR, здесь и далее темно-серые ячейки - комбинации повышенного риска, светло-серые - пониженного риска, белые - сочетания комбинаций генотипов отсутствуют. Столбики слева - количество больных с ЭГ, столбики справа - число индивидуумов контрольной группы; A, B, C, D - обозначение моделей межгенных взаимодействий (данные получены Москаленко М.И [32]).

Fig. 1. Diagram of interaction models of polymorphic $M M P$ loci during the formation of essential hypertension $(\mathrm{EH})$

Note: obtained by the MDR method, hereinafter, dark gray cells - combinations of increased risk, light gray - reduced risk, white - combinations of combinations of genotypes are absent. The bars on the left are the number of patients with $\mathrm{EH}$, the bars on the right are the number of individuals in the control group; A, B, C, D - designation of models of intergenic interactions (data obtained by Moskalenko M.I. [32]). 

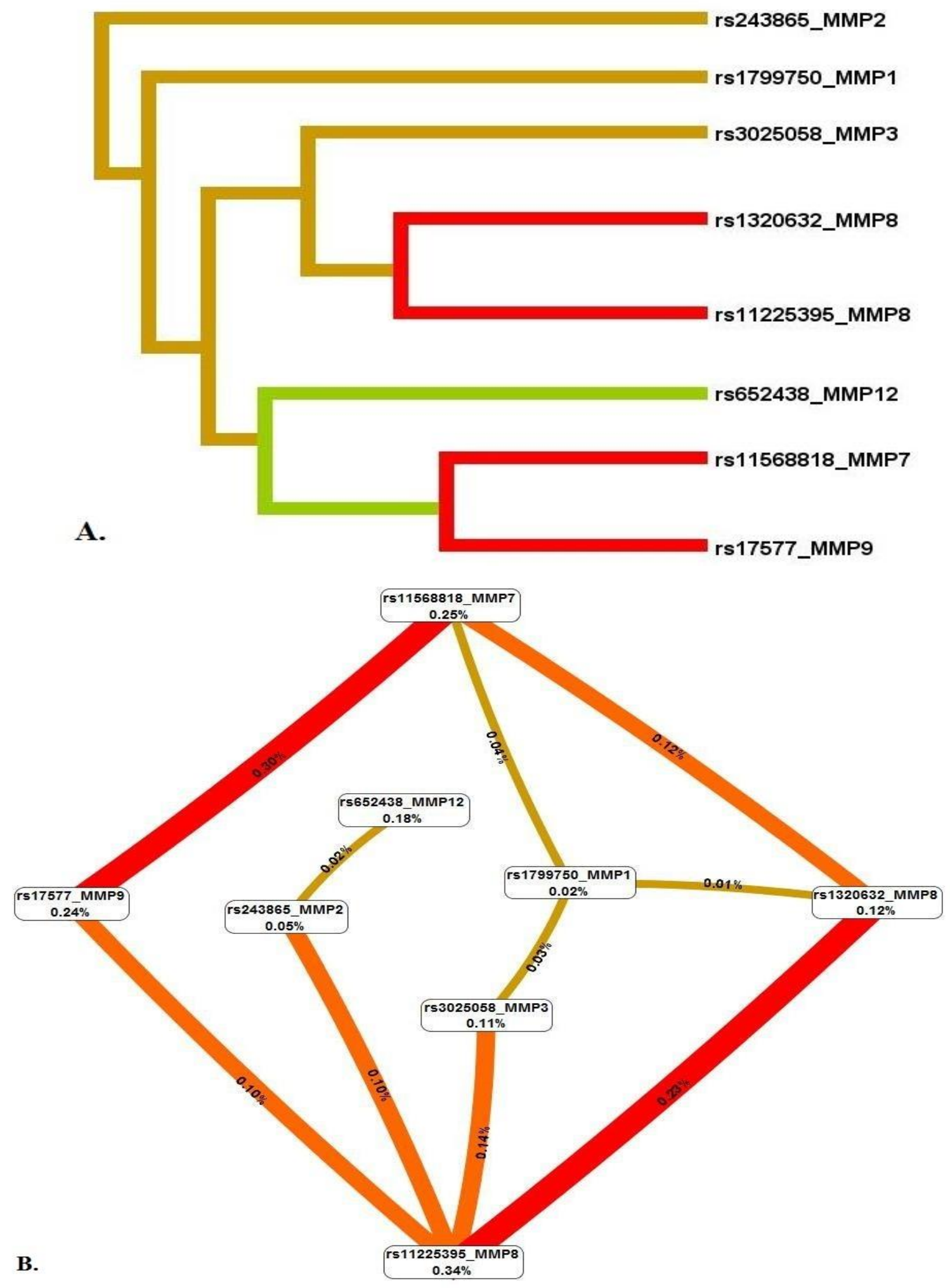

Рис. 2. Дендрограмма (А) и граф (В) межгенных взаимодействий $M M P$ при формировании эссенциальной гипертензии

Примечание: характер взаимодействия между $M M P$ при формировании фенотипа характеризуется цветом линии: красный - выраженный синергизм, оранжевый - умеренный синергизм, синий - коричневый - аддитивное взаимодействие. Сила и направленность взаимодействия выражены в \% энтропии (данные получены Москаленко М.И [32]).

Fig. 2. Dendrogram (A) and graph (B) of intergenic interactions of $M M P$ s during the development of essential hypertension 
Note: the nature of the interaction between the $M M P$ in the formation of the phenotype is characterized by the color of the line: red - pronounced synergism, orange - moderate synergism, blue - brown additive interaction. The strength and direction of interaction are expressed in\% entropy (data obtained by Moskalenko M.I. [32]).

Таким образом, метод MDR дает возможность оценивать ген-генные и генносредовые взаимодействия, ассоциированные с качественными фенотипами с учетом коррекции на качественные ковариаты и проводить валидацию с помощью пермутационного теста. Так же он позволяет проводить кросс-валидацию моделей (определение показателей согласованности (CVC), точности предсказания (Testing Balanced Accuracy), чувствительности $\left(\mathrm{S}_{\mathrm{e}}\right)$ и специфичности $\left(\mathrm{S}_{\mathrm{p}}\right)$ моделей), оценивать характер (synergy, additive, redundancy) и силу (доля вклада в энтропию) SNP $\times$ SNP и генно-средовых взаимодействий и их визуализировать в виде графа. При этом, данный метод не дает возможность изучать количественные фенотипы и учитывать количественные ковариаты, а также получать точное значение $\mathrm{p}_{\text {perm. }}$

К настоящему времени разработано достаточно большое количество модификаций метода MDR - Generalized MDR (GMDR), Pedigree-based GMDR (PGMDR), Cox-based MDR (Cox-MDR), Pair-wise MDR (PW-MDR), Quantitative MDR (QMDR) и др. [7], адаптированные под отдельные программные оболочки (MATLAB, Java, Python, R и др.) и характеризующиеся своими «исследовательскими» особенностями: возможность учитывать качественные и количественные ковариаты при анализе, изучение небольших обьемов выборок, исследование качественных и количественных фенотипов, проведение пермутационных процедур и т.д. С более детальными характеристиками этих модификаций метода MDR можно ознакомиться в работе Gola D et al. [7]. В настоящей работе мы рассмотрим две модификации метода MDR - MBMDR и GMDR, которые мы использовали в наших исследованиях.

Метод Model-Based-MDR (MB-MDR), в отличие от MDR, позволяет анализировать межгенные взаимодействия, ассоциированные как с качественными (развитие заболевания), так и с количественными признака- ми, учитывать в анализе ковариаты и проводить валидацию полученных моделей с помощью пермутационного теста. Следует отметить, что метод MB-MDR, отличается высокой статистической мощностью при наличии генетической гетерогенности [33, 34]. При проведении MD-MDR анализа выделяются 3 категории генотипов - высокого риска, низкого риска и не влияющие на риск. Далее каждая группа комбинаций генотипов сравнивается с двумя другими группами и результатом этого является выделение нескольких комбинаций генотипов, связанных (согласно статистики Вальда и уровня значимости ассоциации) с исследуемым фенотипом. Далее для каждой тестируемой комбинации выбирается вариант, соответствующий максимальному значению статистики Вальда и затем определяется экспериментальный уровень значимости с помощью пермутационного теста.

При использовании метода MD-MDR наиболее оптимальной является кодоминантная схема кодирования полиморфных локусов, обеспечивающая наилучший баланс между уровнем ошибки 1-го рода и мощностью исследования $[35,36]$. В рамках метода MD-MDR проводится тестирование как правило двух-, трех- и четырехлокусных (факторных) комбинаций. Хотя данный метод позволяет учитывать комбинации и большего числа факторов. При необходимости в анализ включаются ковариаты (как качественные, так и количественные). В конечном итоге рассматриваются модели (в среднем 3-4 модели каждого уровня) с наибольшими статистиками Вальда и уровнем значимости. Валидация результатов проводится с помощью пермутационного теста. Также, с помощью метода MB-MDR устанавливаются отдельные комбинации генотипов (и факторов риска), ассоциированные с исследуемыми фенотипами, с расчетом их статистической значимости. Метод MB-MDR (Model Based Multifactor Dimensionality Reduction) реализован в про- 
граммном обеспечении MB-MDR (Version 2.6) для программной среды $\boldsymbol{R}$.

Таким образом, метод MB-MDR позволяет анализировать межгенные и генносредовые взаимодействия, ассоциированные с качественными и количественными фенотипами, учитывать в анализе ковариаты, проводить валидацию полученных моделей с помощью пермутационного теста, а также определять отдельные комбинации генотипов (и факторов среды), ассоциированные с исследуемыми фенотипами с учетом их уровня значимости. При этом, программное обеспечение метода MB-MDR не дает возможность визуализировать графически (в виде графа или дендрограммы) установленные ген-генные и генно-средовые взаимодействия.

Метод Generalized MDR (GMDR) [37, 38] (http://www.ssg.uab.edu/gmdr), реализованный в программном обеспечении GMDR (software Beta

(http://sourceforge.net/projects/gmdr) является модификацией метода MDR и основан на тех же принципах что и этот метод. Он позволяет оценивать ассоциации качественных фенотипов с различными комбинациями генотипов и факторов среды в рамках 2-х, 3-х, n-локусных моделей. Следует отметить, что программное обеспечение метода GMDR позволяет построить граф (дендрограмму) и таким образом визуализировать рассматриваемые ген-генные и генно-средовые взаимодействия, а также оценить характер этих взаимодействий (synergy, additive, redundanсу). При расчетах метод GMDR позволяет учитывать как качественные, так и количественные ковариаты. Данный метод дает возможность проводить кросс-валидацию наиболее значимых моделей с расчетом показателей согласованности (CVC), точности предсказания (Testing Balanced Accuracy), чувствительности $\left(\mathrm{S}_{\mathrm{e}}\right)$ и специфичности $\left(\mathrm{S}_{\mathrm{p}}\right)$ моделей, при этом так же учитываются ковариаты. Коррекция на множественные сравнения проводится с помощью пермутационного теста в Perl script ("perl GMDR_permutatin.pl”) программного обеспечения GMDR (software Beta 0.9). При этом указывается необходимое количество пермутаций (разработчики метода GMDR отмечают, что для получения р-значения на уровне 0,001 необходимо 1000 пермутаций, а для получения р-значения на уровне 0,0001 должно быть 10000 пермутаций) и необходимой число кросс-валидаций (разработчики указывают, что при обьеме выборки до 500 человек достаточно 5 кроссвалидаций, а при выборке более 1000 человек необходимо 10 кросс-валидаций). При пермутационном тесте так же возможна коррекция на ковариаты. Следует отметить, что метод GMDR не позволяет изучать генгенные и генно-средовые взаимодействия, ассоциированные с количественными признаками.

В таблице 1 и на рисунке 3 представлены данные, полученные Милановой С.Н. [39] с использованием метода GMDR при анализе генно-средовых взаимодействий полиморфных локусов цитокинов с употреблением алкоголя, ассоциированных с развитием инсульта на фоне гипертонической болезни. В таблице приведены наиболее значимые модели генно-средовых взаимодействий, ассоциированные с развитием инсульта на фоне гипертонической болезни, а также результаты их кросс-валидации (показатели воспроизводимости моделей (CVC) и точности предсказания моделей (Test Bal. Acc.)) и пермутационных процедур. На рисунке 6 представлены дендрограмма (А) и граф (В) генно-средовых взаимодействий, ассоциированные с развитием инсульта на фоне гипертонической болезни, демонстрирующие характер этих взаимодействий (synergy, additive, redundancy) и их силу (доля вклада в энтропию). 
Наиболее значимые модели генно-средовых взаимодействий полиморфных локусов Таблица 1 цитокинов с употреблением алкоголя, ассоциированные с развитием инсульта на фоне гипертонической болезни

Table 1

The most significant models of gene-environment interactions of polymorphic cytokine loci with alcohol use, associated with the development of stroke associated with hypertension

\begin{tabular}{|c|c|c|c|c|}
\hline Модель & $\begin{array}{c}\text { Модель генно-средовых } \\
\text { взаимодействий }\end{array}$ & $\begin{array}{c}\mathrm{OR} \\
(95 \% \mathrm{CI})\end{array}$ & $\begin{array}{l}\text { Test Bal. } \\
\text { Acc. }\end{array}$ & $\mathrm{p}$ \\
\hline A & 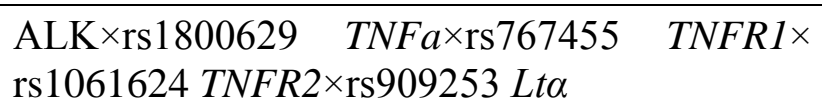 & $\begin{array}{l}3,84 \\
(2,40-6,14)\end{array}$ & 59,42 & 0,001 \\
\hline B & $\begin{array}{l}\mathrm{ALK} \times \mathrm{rs} 1800629 \quad T N F a \times \mathrm{rs} 767455 \\
\mathrm{rs} 1061624 T N F R 2 \times \mathrm{rs} 6214 I G F 1\end{array}$ & $\begin{array}{l}3,25 \\
(2,06-5,12)\end{array}$ & 53,29 & 0,011 \\
\hline
\end{tabular}

Примечание: получены в программе GMDR с коррекцией на уровни ТГ, ЛПВП, курение, подверженность частым стрессовым ситуациям; воспроизводимость моделей (CVC) составила 100\%; Test Bal. Acc. - точность предсказания модели (\%), проведен пермутационный тест выполнено 1000 пермутаций при 10 кросс-валидациях, что обеспечивает $\mathrm{p}_{\text {perm }}<0,001$ (данные получены Милановой С.Н. [39]).

Note: obtained in the GMDR program with correction for levels of TG, HDL, smoking, exposure to frequent stressful situations; model reproducibility (CVC) was 100\%; Test Bal. Acc. - model prediction accuracy (\%), permutation test was carried out -1000 permutations were performed with 10 cross-validations, which ensures perm $<0.001$ (data obtained by Milanova S.N. [39]).

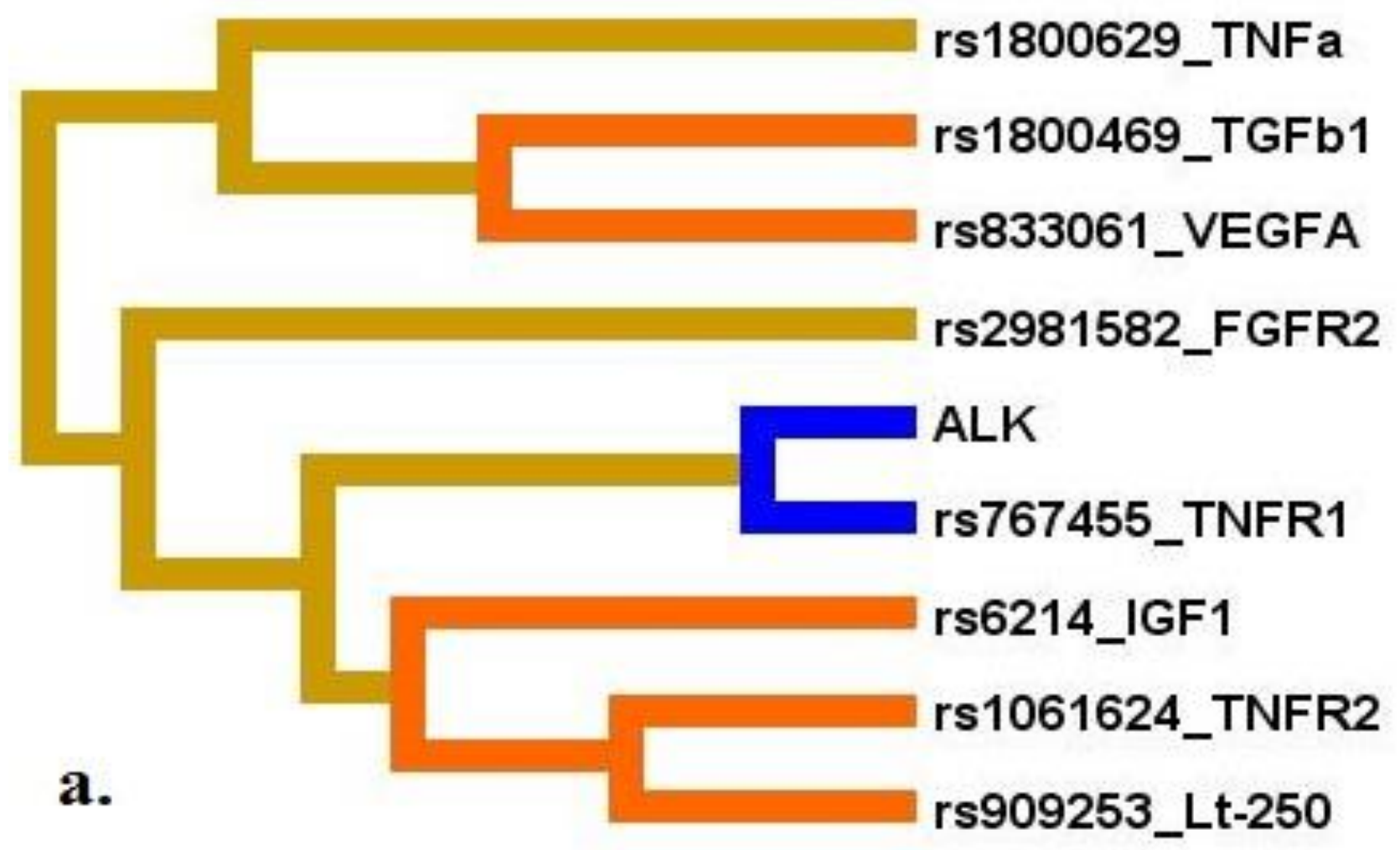




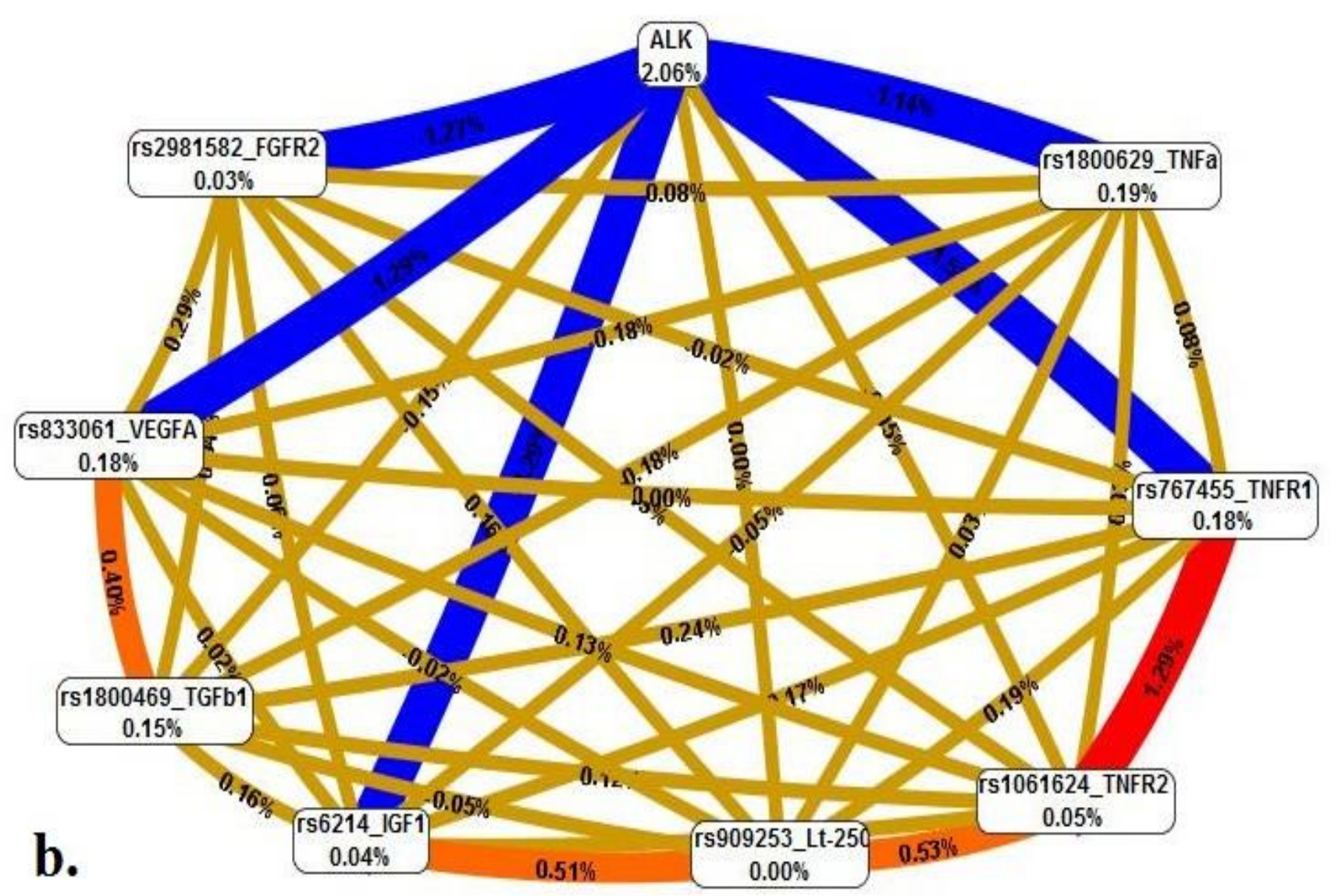

Рис. 3. Дендрограмма (А) и граф (В) генно-средовых взаимодействий полиморфных локусов цитокинов и употребления алкоголя при формировании ишемического инсульта на фоне гипертонической болезни

Примечание: направленность взаимодействий между генами-кандидатами при формировании фенотипа обозначаются линиями разного цвета: красного - выраженный синергизм, оранжевого умеренный синергизм, синего - выраженный антагонизм, зеленого - умеренный антагонизм, коричневого - аддитивное взаимодействие. Сила и направленность взаимодействий представлены в \% энтропии (данные получены Милановой С.Н. [39]).

Fig. 3. Dendrogram (A) and graph (B) of gene-environmental interactions of polymorphic loci of cytokines and alcohol use during the development of ischemic stroke associated with hypertension Note: the orientation of the interactions between candidate genes during the formation of the phenotype is indicated by lines of different colors: red - pronounced synergism, orange - moderate synergism, blue - pronounced antagonism, green - moderate antagonism, brown - additive interaction. The strength and direction of interactions are represented in\% entropy (data obtained by Milanovoy S.N. [39]).

Таким образом, метод GMDR дает возможность оценивать ген-генные и генносредовые взаимодействия, ассоциированные с качественными фенотипами с учетом коррекции на качественные и количественные ковариаты, проводить валидацию с помощью пермутационного теста, оценивать ха- рактер (synergy, additive, redundancy) и силу (доля вклада в энтропию) $\mathrm{SNP} \times \mathrm{SNP}$ и генно-средовых взаимодействий и их визуализировать в виде графа. Так же метод GMDR позволяет проводить кросс-валидацию наиболее значимых моделей взаимодействий с учетом коррекции на ковариаты и 
коррекцию на множественные сравнения с помощью пермутационного теста.

В качестве примера эффективности использования метода MDR и его модификации MB-MDR для оценки ген-генных взаимодействий, ассоциированных с формированием количественных мультифакториальных признаков, приведем полученные нами результаты генетико-эпидемиологического исследования возраста менархе, опубликованные в журналах GENE [40]. Нами с помощью метода MB-MDR изучены ассоциации ген-генных взаимодействий 52 SNPs c возрастом менархе у женщин России. Выборка для исследования составила 1613 женщин. Для генетико-статистического анализа использовались трансформированные значения возраста менархе в связи с тем, что его распределение в исследуемой выборке отличалось от нормального. Изучение межгенных взаимодействий проводилось с коррекцией на коварианты - год рождения (дискретная переменная) и наличие изолированных или сочетанных доброкачественных опухолей и гиперпластических процессов матки (дискретная переменная). В работу включались наиболее значимые модели ген-генных взаимодействий: $p<1 * 10^{-4}$ для двухлокусных моделей, $p<1 * 10^{-7}$ для трехлокусных моделей, $p<1 * 10^{-12}$ для четырехлокусных моделей. Коррекция на множественные сравнения проводилась с помощью пермутационного теста (выполнялось 1000 пермутаций) для отобранных для исследования наиболее значимых 2-х, 3-х и 4-х локусных моделей. Статистически значимыми считали модели c $p_{\text {perm }}<0,01$. Оценка характера (synergy, additive, redundancy) и силы (доля вклада в энтропию) межгенных взаимодействий, а также их визуализация в виде графа проводилась с помощью метода MDR. Установлено, что 14 полиморфных локусов из 52 изученных SNPs ассоциированы с возрастом менархе в составе 12 наиболее значимых 2-х, 3-х и 4-х локусных моделей ген-генных взаимодействий $\left(\mathrm{p}_{\text {perm }} \leq 0,006\right)$. Выявлены антагонистические взаимодействия 4 полиморфных локусов (определяют -0,25 - $0,39 \%$ энтропии признака) (рисунок 4) rs6438424 3q13.32, rs1073768 GHRH, rs4946651 LIN28B, rs314276 LIN28B (на рисунке линии их объединяющие окрашены в синий цвет) и синергизм (детерминируют 0,31-0,37\% энтропии) в ген-генных взаимодействиях 6 SNPs - rs1073768 GHRH, rs7579411 LHCGR, rs7759938 LIN28B, rs4374421 LHCGR, rs6589964 BSX, rs10769908 STK33 (на рисунке линии их объединяющие окрашены в красный цвет).

Итак, проведенный анализ литературных данных позволяет заключить, что при изучении ассоциаций полиморфных локусов с мультифакториальными признаками (как качественными - заболеваниями, так и количественными) наиболее оптимальным является использование вначале метода MBMDR для установления наиболее значимых $\mathrm{SNP} \times \mathrm{SNP}$ и генно-средовых взаимодействий, их валидация с помощью пермутационного теста, а также определение конкретных комбинаций, ассоциированных с развитием исследуемого фенотипа. Далее с помощью метода GMDR проведение кроссвалидации наиболее значимых моделей взаимодействий с учетом коррекции на ковариаты и коррекцию на множественные сравнения с помощью пермутационного теста. Затем использование метода MDR для оценки характера (synergy, additive, redundancy) и силы (доля вклада в энтропию) SNP $\times$ SNP и генно-средовых взаимодействий и их визуализации в виде графа. 


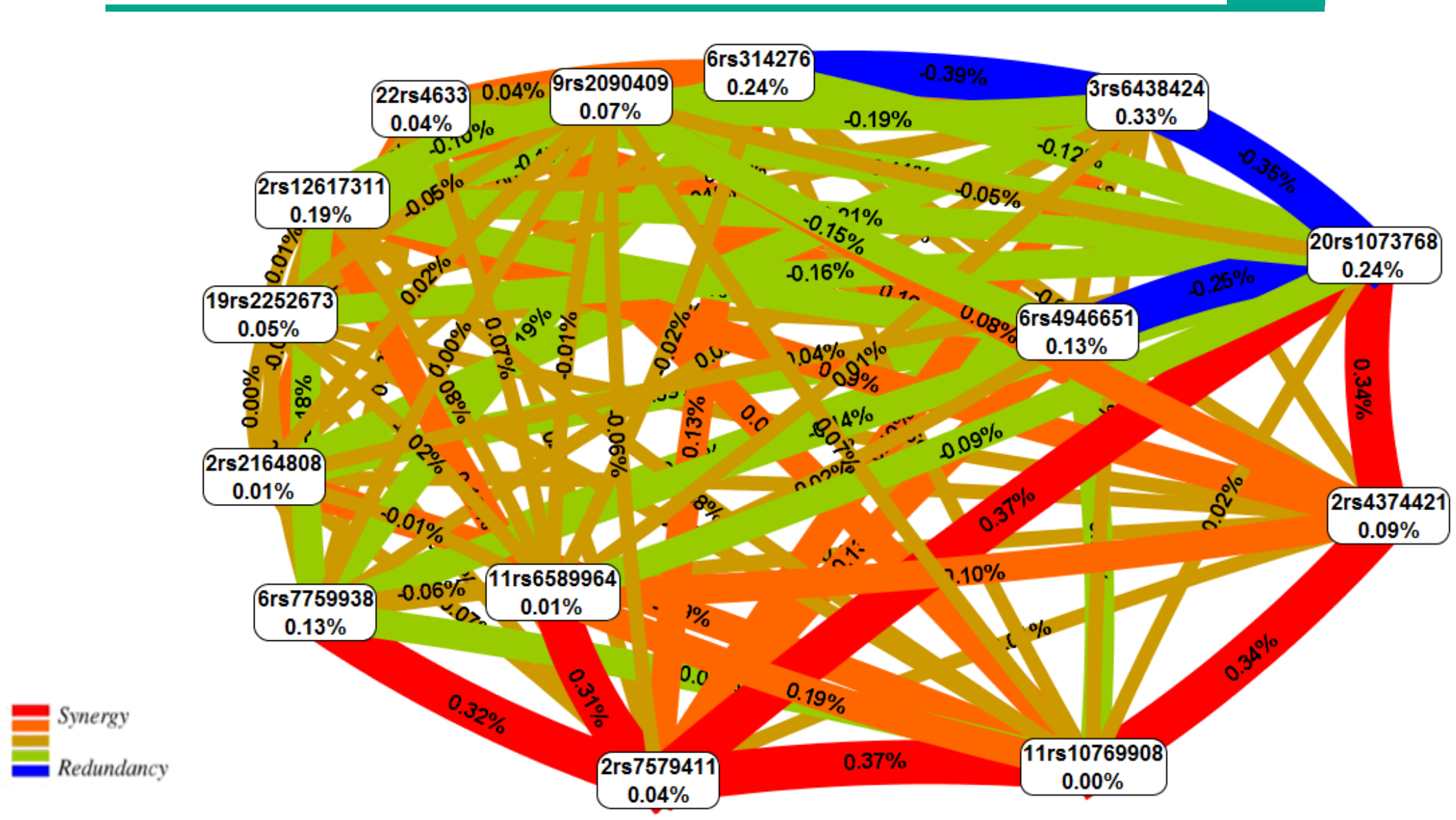

Рис. 4. Граф SNP×SNP взаимодействий, ассоциированных с возрастом менархе (получен методом MDR)

Примечание: Характеризует силу и направленность влияния полиморфизмов или сочетания полиморфизмов на возраст менархе (трансформированные значения) (\% энтропии). При обозначении полиморфизма указаны хромосома и rs SNP. Цвет линии отражает характер взаимодействия между полиморфизмами: красный и оранжевый указывает на выраженный и умеренный синергизм, коричневый - независимый эффект отдельных локусов, зеленый и синий - умеренный и выраженный антагонизм соответственно [40].

Fig. 4. Graph SNP $\times$ SNP interactions associated with menarche age (obtained by the MDR method)

Note: Characterizes the strength and directionality of the influence of polymorphisms or combinations of polymorphisms on the age of menarche (transformed values) (\% entropy). When referring to a polymorphism, the chromosome and rs SNP are indicated. The color of the line reflects the nature of the interaction between polymorphisms: red and orange indicates pronounced and moderate synergism, brown indicates the independent effect of individual loci, green and blue indicates moderate and pronounced antagonism, respectively [40]. 
В отношении данной статьи не было зарегистрировано конфликта интересов.

\section{Список литературы}

1. Dvornyk V., Haq W. Genetics of age at menarche: a systematic review // Human Reproduction Update. 2012. Vol. 18(2). P. 198-210. DOI: https://doi.org/10.1093/humupd/dmr050

2. Genome-wide association studies and epistasis analyses of candidate genes related to age at menarche and age at natural menopause in a Korean population / J.A. Pyun [et al.] // Menopause. 2014. N 21. P. 522-9. DOI: 10.1097/GME.0b013e3182a433f7

3. A Novel Polymorphism in the Promoter of the CYP4A11 Gene Is Associated with Susceptibility to Coronary Artery Disease / S. Sirotina [et al.] // Dis Markers. 2018. N 2018. P. 5812802. DOI:10.1155/2018/5812802

4. PLINK: a tool set for whole-genome association and population-based linkage analyses / S. Purcell [et al.] // Am J Hum Genet. 2007. N 81. P. 559-75. DOI: $10.1086 / 519795$

5. A Markov Chain Monte Carlo Technique for Identification of Combinations of Allelic Variants Underlying Complex Diseases in Humans / A.V. Favorov [et al.] // Genetics. 2005. Vol. 171(4). P. 2113-2121. DOI: 1534/genetics.105.048090

6. Lvovs D., Favorova O.O., Favorov A.V. A Polygenic Approach to the Study of Polygenic Diseases // Acta naturae. 2012. Vol. 4(3(14)). P. 59-71.

7. A roadmap to multifactor dimensionality reduction methods / D. Gola [et al.] // Brief Bioinform. 2015. Vol. 17(2). P. 293-308. DOI: https://doi.org/10.1093/bib/bbv038

8. Multifactor-dimensionality reduction reveals high-order interactions among estrogenmetabolism genes in sporadic breast cancer / M.D. Ritchie [et al.] // Am J Hum Genet. 2001. Vol. 69(1). P. 138-47. DOI: https://doi.org/10.1086/321276

9. Genome Wide Association Study of Age at Menarche in the Japanese Population / C. Tanikawa [et al.] // PLoS ONE. 2013. Vol. 8(5). P. e63821. DOI:10.1371/journal.pone.0063821

10. Reverse Pathway Genetic Approach Identifies Epistasis in Autism Spectrum Disorders / I. Mitra [et al.] // PLoS Genet. 2017. Vol. 13(1). P. e1006516. DOI:10.1371/journal.pgen.1006516

11. Combinations of Polymorphic Markers of Chemokine Genes, Their Receptors and Acute Phase Protein Genes As Potential Predictors of
Coronary Heart Diseases / T.R. Nasibullin [et al.] // Acta Naturae. 2016. Vol. 8(1). P. 111-6.

12. Variants of the Coagulation and Inflammation Genes Are Replicably Associated with Myocardial Infarction and Epistatically Interact in Russians / R.M. Barsova [et al.] // PLoS One. 2015. Vol. 10(12). P. DOI:10.1371/journal.pone.0144190

13. Variants of MicroRNA Genes: Gender-Specific Associations with Multiple Sclerosis Risk and Severity / I. Kiselev [et al.] // Int J Mol Sci. 2015. Vol. 16(8). P. 20067-81. DOI:10.3390/ijms160820067

14. Genes of tumor necrosis factors and their receptors and the primary open angle glauco$\mathrm{ma}$ in the population of Central Russia / E. Tikunova [et al.] // Int J Ophthalmol. 2017. Vol. 10(10).

P. 1490-1494. DOI:10.18240/ijo.2017.10.02

15. A Comparative Study on Multifactor Dimensionality Reduction Methods for Detecting Gene-Gene Interactions with the Survival Phenotype / S. Lee [et al.] // Biomed Res Int. 2015. N 2015. P. 671859. DOI: http://dx.doi.org/10.1155/2015/671859

16. A Multiple Interaction Analysis Reveals ADRB3 as a Potential Candidate for Gallbladder Cancer Predisposition via a Complex Interaction with Other Candidate Gene Variations / R. Rai [et al.] // Int J Mol Sci. 2015. Vol. 16(12). P. 28038-49. DOI:10.3390/ijms161226077

17. Gene-gene and gene-environmental interactions of childhood asthma: a multifactor dimension reduction approach / M.W. Su [et al.] // PLoS One. 2012. Vol. 7(2). P. e30694. DOI: https://doi.org/10.1371/journal.pone.0030694

18. Interactions between genetic variants in AMH and AMHR2 may modify age at natural menopause / M.G. Braem [et al.] // PLoS One. 2013. Vol. 8(3). P. e59819. DOI: https://doi.org/10.1371/journal.pone.0059819

19. The Cumulative Effect of Gene-Gene and Gene-Environment Interactions on the Risk of Prostate Cancer in Chinese Men / M. Liu [et al.] // Int J Environ Res Public Health. 2016. Vol. 13(2). P. 162. DOI:10.3390/ijerph13020162

20.Exploring the interaction among EPHX1, GSTP1, SERPINE2, and TGFB1 contributing to the quantitative traits of chronic obstructive pulmonary disease in Chinese Han population / L. An [et al.] // Hum Genomics. 2016. Vol. 10(1). P. 13. DOI:10.1186/s40246-016-0076-0

21.Effects of High-Order Interactions among IGFBP-3 Genetic Polymorphisms, Body Mass In- 
dex and Soy Isoflavone Intake on Breast Cancer Susceptibility / Q. Wang [et al.] // PLoS One. 2016. Vol. 11(9). P. DOI:10.1371/journal.pone.0162970

22.Genetic polymorphisms associated with the inflammatory response in bacterial meningitis / F.L. Fontes [et al.] // BMC Med Genet. 2015. N 16. P. 70. DOI:10.1186/s12881-015-0218-6

23.PACSIN2 polymorphism is associated with thiopurine-induced hematological toxicity in children with acute lymphoblastic leukaemia undergoing maintenance therapy / A. Smid [et al.] // Sci Rep. 2016. N 6. P. 30244. DOI:10.1038/srep30244

24.Interactions among variants in TXA2R, P2Y12 and GPIIIa are associated with carotid plaque vulnerability in Chinese population / X. Yi [et al.] // Oncotarget. 2018. Vol. 9(25). P. 17597-17607. DOI:10.18632/oncotarget.24801

25. Genetic polymorphisms in $\mathrm{CDH} 1$ are associated with endometrial carcinoma susceptibility among Chinese Han women / Y.H. Geng [et al.] // Oncol Lett. 2018. Vol. 16(5). P. 6868-6878. DOI: https://doi.org/10.3892/ol.2018.9469

26.Effect of GRM7 polymorphisms on the development of noise-induced hearing loss in Chinese Han workers: a nested case-control study / P. $\mathrm{Yu}$ [et al.] // BMC Med Genet. 2018. Vol. 19(1). P. 4. DOI:10.1186/s12881-017-0515-3

27.Dvl3 polymorphism interacts with life events and pro-inflammatory cytokines to influence major depressive disorder susceptibility / J. Zhang [et al.] // Sci Rep. 2018. Vol. 8(1). P. 14181. DOI:10.1038/s41598-018-31530-2

28. Childhood trauma interacted with BDNF Val66Met influence schizophrenic symptoms / X.J. Bi [et al.] // Medicine (Baltimore). 2018. Vol. 97(13). P. e0160. DOI: 10.1097/MD.0000000000010160

29.Polymorphisms of CYP2C8, CYP2C9 and CYP2C19 and risk of coronary heart disease in Russian population / A. Polonikov [et al.] // Gene. 2017. N 627. P. 451-459. DOI: 10.1016/j.gene.2017.07.004

30.A comprehensive contribution of genes for aryl hydrocarbon receptor signaling pathway to hypertension susceptibility / A.V. Polonikov [et al.] // Pharmacogenet Genomics. 2017. Vol. 27(2). P. 57-69. DOI: $10.1097 / F P C .0000000000000261$

31.A flexible computational framework for detecting, characterizing, and interpreting statistical patterns of epistasis in genetic studies of human disease susceptibility / J. Moore [et al.] // Journal of Theoretical Biology. 2006. Vol. 241(2). P. 252-261. DOI: https://doi.org/10.1016/j.jtbi.2005.11.036
32.Москаленко М.И. Вклад генетических полиморфизмов матриксных металлопротеиназ в формирование предрасположенности к эссенциальной гипертензии: дис. ... канд. биол. наук. Белгород, 2017. 231c.

33.Mbmdr: an R package for exploring genegene interactions associated with binary or quantitative traits / M.L. Calle [et al.] // Bioinformatics. 2010. Vol. 26(17). P. 2198-2199. DOI: https://doi.org/10.1093/bioinformatics/btq352

34.Improving strategies for detecting genetic patterns of disease susceptibility in association studies / M.L. Calle [et al.] // Stat Med. 2008. Vol. 27(30). P. 6532-6546. DOI: https://doi.org/10.1002/sim.3431

35. Mahachie John JM, Van Lishout F, Van Steen K. Model-Based Multifactor Dimensionality Reduction to detect epistasis for quantitative traits in the presence of error-free and noisy data // Eur J Hum Genet. 2011. Vol. 19(6). P. 696-703. DOI: https://doi.org/10.1038/ejhg.2011.17

36.Lower-order effects adjustment in quantitative traits model-based multifactor dimensionality reduction / John JM Mahachie [et al.] // PLoS One. 2012. Vol. 7(1). P. e29594. DOI: https://doi.org/10.1371/journal.pone.0029594

37. A generalized combinatorial approach for detecting gene by gene and gene by environment interactions with application to nicotine dependence / X.Y. Lou [et al.] // American Journal of Human Genetics. 2007. Vol. 80(6). P. 1125-1137. DOI: https://doi.org/10.1086/518312

38.Practical and theoretical considerations in study design for detecting gene-gene interactions using MDR and GMDR approaches / G.B. Chen [et al.] // PLoS One. 2011. N 6. P. e16981. DOI: https://doi.org/10.1371/journal.pone.0016981

39. Миланова С.Н. Анализ ассоциаций полиморфных маркеров генов-кандидатов и генно-средовых взаимодействий с формированием гипертонической болезни и ее осложнений: дис. ... канд. мед. наук. Белгород, 2018.

40. Association of genetic polymorphisms with age at menarche in Russian women / I. Ponomarenko [et al.] // Gene. 2019. N 686. P. 228236. https://doi.org/10.1016/j.gene.2018.11.042 


\section{References}

1. Dvornyk V, Haq W. Genetics of age at menarche: a systematic review. Human Reproduction Update. 2012;18(2):198-210. DOI: https://doi.org/10.1093/humupd/dmr050

2. Pyun JA, Kim S, Cho NH, et al. Genome-wide association studies and epistasis analyses of candidate genes related to age at menarche and age at natural menopause in a Korean population. Menopause. 2014;21:522-9. DOI: 10.1097/GME.0b013e3182a433f7

3. Sirotina S, Ponomarenko I, Kharchenko A, et al. A Novel Polymorphism in the Promoter of the CYP4A11 Gene Is Associated with Susceptibility to Coronary Artery Disease. Dis Markers. 2018;2018:5812802. DOI:10.1155/2018/5812802

4. Purcell S, Neale B, Todd-Brown K, et al. PLINK: a tool set for whole-genome association and population-based linkage analyses. Am J Hum Genet. 2007;81:559-75. DOI: 10.1086/519795

5. Favorov AV, Andreewski TV, Sudomoina MA, et al. A Markov Chain Monte Carlo Technique for Identification of Combinations of Allelic Variants Underlying Complex Diseases in Humans. Genetics. 2005;171(4):2113-2121. DOI: 1534/genetics. 105.048090

6. Lvovs D, Favorova OO, Favorov AV. A Polygenic Approach to the Study of Polygenic Diseases. Acta naturae. 2012;4(3(14)):59-71.

7. Gola D, Mahachie John JM, van Steen $\mathrm{K}$, et al. A roadmap to multifactor dimensionality reduction methods. Brief Bioinform. 2015;17(2):293-308. DOI: https://doi.org/10.1093/bib/bbv038

8. Ritchie MD, Hahn LW, Roodi N, et al. Multifactor-dimensionality reduction reveals highorder interactions among estrogen-metabolism genes in sporadic breast cancer. Am J Hum Genet. 2001;69(1):138-47.

DOI: https://doi.org/10.1086/321276

9. Tanikawa C, Okada Y, Takahashi A, et al. Genome Wide Association Study of Age at Menarche in the Japanese Population. PLoS ONE. 2013;8(5):e63821.

DOI:10.1371/journal.pone.0063821

10. Mitra I, Lavillaureix A, Yeh E, et al. Reverse Pathway Genetic Approach Identifies Epistasis in Autism Spectrum Disorders. PLoS Genet. 2017;13(1):e1006516.

DOI:10.1371/journal.pgen.1006516

11. Nasibullin TR, Yagafarova LF, Yagafarov IR, et al. Combinations of Polymorphic Markers of Chemokine Genes, Their Receptors and Acute Phase Protein Genes As Potential Predictors of Coronary Heart Diseases. Acta Naturae. 2016;8(1):111-6.

12. Barsova RM, Lvovs D, Titov BV, et al. Variants of the Coagulation and Inflammation Genes Are Replicably Associated with Myocardial Infarction and Epistatically Interact in Russians. PLoS One. 2015;10(12):e0144190. DOI:10.1371/journal.pone.0144190

13. Kiselev I, Bashinskaya V, Kulakova O, et al. Variants of MicroRNA Genes: GenderSpecific Associations with Multiple Sclerosis Risk and Severity. Int J Mol Sci. 2015;16(8):20067-81. DOI:10.3390/ijms160820067

14. Tikunova E, Ovtcharova V, Reshetnikov E, et al. Genes of tumor necrosis factors and their receptors and the primary open angle glaucoma in the population of Central Russia. Int $\mathbf{J}$ Ophthalmol. 2017;10(10):1490-1494. DOI:10.18240/ijo.2017.10.02

15. Lee S, Kim Y, Kwon MS, et al. A Comparative Study on Multifactor Dimensionality Reduction Methods for Detecting Gene-Gene Interactions with the Survival Phenotype. Biomed Res Int. 2015;2015:671859. DOI: http://dx.doi.org/10.1155/2015/671859

16. Rai R, Kim JJ, Misra S, et al. A Multiple Interaction Analysis Reveals ADRB3 as a Potential Candidate for Gallbladder Cancer Predisposition via a Complex Interaction with Other Candidate Gene Variations. Int J Mol Sci. 2015;16(12):28038-49.

DOI:10.3390/ijms 161226077

17.Su MW, Tung KY, Liang PH, et al. Genegene and gene-environmental interactions of childhood asthma: a multifactor dimension reduction approach. PLoS One. 2012;7(2):e30694. DOI: https://doi.org/10.1371/journal.pone.0030694

18. Braem MG, Voorhuis M, van der Schouw YT, et al. Interactions between genetic variants in AMH and AMHR2 may modify age at natural menopause. PLoS One. 2013;8(3):e59819. DOI: https://doi.org/10.1371/journal.pone.0059819

19.Liu M, Shi X, Yang F, et al. The Cumulative Effect of Gene-Gene and Gene-Environment Interactions on the Risk of Prostate Cancer in Chinese Men. Int $J$ Environ Res Public Health. 2016;13(2):162. DOI:10.3390/ijerph13020162

20. An L, Lin Y, Yang T, et al. Exploring the interaction among EPHX1, GSTP1, SERPINE2, and TGFB1 contributing to the quantitative traits of chronic obstructive pulmonary disease in Chinese Han population. Hum Genomics. 2016;10(1):13. DOI:10.1186/s40246-016-0076-0

21.Wang Q, Liu L, Li H, et al. Effects of High-Order Interactions among IGFBP-3 Genetic 
Polymorphisms, Body Mass Index and Soy Isoflavone Intake on Breast Cancer Susceptibility. PLoS One. 2016;11(9):e0162970. DOI:10.1371/journal.pone.0162970

22.Fontes FL, de Araújo LF, Coutinho LG, et al. Genetic polymorphisms associated with the inflammatory response in bacterial meningitis. BMC Med Genet. 2015;16:70. DOI:10.1186/s12881-0150218-6

23.Smid A, Karas-Kuzelicki N, Jazbec J, et al. PACSIN2 polymorphism is associated with thiopurine-induced hematological toxicity in children with acute lymphoblastic leukaemia undergoing maintenance therapy. Sci Rep. 2016;6:30244. DOI:10.1038/srep30244

24.Yi X, Lin $\mathrm{J}$, Luo $\mathrm{H}$, et al. Interactions among variants in TXA2R, P2Y12 and GPIIIa are associated with carotid plaque vulnerability in Chinese population. Oncotarget. 2018;9(25):1759717607. DOI: $10.18632 /$ oncotarget. 24801

25.Geng YH, Wang ZF, Jia YM, et al. Genetic polymorphisms in $\mathrm{CDH} 1$ are associated with endometrial carcinoma susceptibility among Chinese Han women. Oncol Lett. 2018;16(5):6868-6878. DOI: https://doi.org/10.3892/ol.2018.9469

26. Yu P, Jiao J, Chen G, et al. Effect of GRM7 polymorphisms on the development of noise-induced hearing loss in Chinese Han workers: a nested case-control study. BMC Med Genet. 2018;19(1):4. DOI:10.1186/s12881-017-0515-3

27.Zhang J, Yang J, Han D, et al. Dvl3 polymorphism interacts with life events and proinflammatory cytokines to influence major depressive disorder susceptibility. Sci Rep. 2018;8(1):14181. DOI:10.1038/s41598-018-315302

28.Bi XJ, Lv XM, Ai XY, et al. Childhood trauma interacted with BDNF Val66Met influence schizophrenic symptoms. Medicine (Baltimore). 2018;97(13):e0160.

DOI:

\subsection{7/MD.0000000000010160}

29.Polonikov A, Kharchenko A, Bykanova $\mathrm{M}$, et al. Polymorphisms of CYP2C8, CYP2C9 and CYP2C19 and risk of coronary heart disease in Russian population. Gene. 2017;627:451-459. DOI: 10.1016/j.gene.2017.07.004

30.Polonikov AV, Bushueva OY, Bulgakova IV, et al. A comprehensive contribution of genes for aryl hydrocarbon receptor signaling pathway to hypertension susceptibility. Pharmacogenet Genomics. 2017;27(2):57-69. DOI: 10.1097/FPC.0000000000000261

31. Moore J, Gilberta J, Tsaif C, et al. A flexible computational framework for detecting, characterizing, and interpreting statistical patterns of epi- stasis in genetic studies of human disease susceptibility. Journal of Theoretical Biology. 2006;241(2):252-261. DOI: https://doi.org/10.1016/j.jtbi.2005.11.036

32. Moskalenko MI. [Contribution of genetic polymorphisms of matrix metalloproteinases to the formation of susceptibility to essential hypertension / thesis for the degree of candidate of biological sciences] [dissertation]. Belgorod; 2017.

33. Calle ML, Urrea $\mathrm{V}$, Malats $\mathrm{N}$, et al. Mbmdr: an $\mathrm{R}$ package for exploring gene-gene interactions associated with binary or quantitative traits. Bioinformatics. 2010;26(17):2198-2199. DOI: https://doi.org/10.1093/bioinformatics/btq352

34.Calle ML, Urrea V, Vellalta G, et al. Improving strategies for detecting genetic patterns of disease susceptibility in association studies. Stat Med. 2008;27(30):6532-6546. DOI: https://doi.org/10.1002/sim.3431

35. Mahachie John JM, Van Lishout F, Van Steen K. Model-Based Multifactor Dimensionality Reduction to detect epistasis for quantitative traits in the presence of error-free and noisy data. Eur $\mathbf{J}$ Hum Genet. 2011;19(6):696-703. DOI: https://doi.org/10.1038/ejhg.2011.17

36. Mahachie John JM, Cattaert T, Lishout $\mathrm{FV}$, et al. Lower-order effects adjustment in quantitative traits model-based multifactor dimensionality reduction. PLoS One. 2012;7(1):e29594. DOI: https://doi.org/10.1371/journal.pone.0029594

37.Lou XY, Chen GB, Yan L, et al. A generalized combinatorial approach for detecting gene by gene and gene by environment interactions with application to nicotine dependence. American Journal of Human Genetics. 2007;80(6):1125-1137. DOI: https://doi.org/10.1086/518312

38.Chen GB, Xu Y, Xu HM, et al. Practical and theoretical considerations in study design for detecting gene-gene interactions using MDR and GMDR approaches. PLoS One. 2011. N 6. P. e16981. https://doi.org/10.1371/journal.pone.0016981

39. Milanova S.N. [Analysis of the associations of polymorphic markers of candidate genes and gene-environmental interactions with the development of hypertension and its complications] [dissertation]. Belgorod; 2018.

40.Ponomarenko I, Reshetnikov E, Altukhova $\mathrm{O}$, et al. Association of genetic polymorphisms with the age at menarche in Russian women. Gene. 2019;686:228-236. DOI: https://doi.org/10.1016/j.gene.2018.11.042 
Информация об авторах

Ирина Васильевна Пономаренко, кандидат медицинских наук, доцент кафедры медикобиологических дисциплин, ФГАОУ ВО «Белгородский государственный национальный исследовательский университет», E-mail: ponomarenko_i@bsu.edu.ru, ORCID: 0000-00025652-0166.

Information about the author

Irina V. Ponomarenko, Candidate of Medical Sciences, Associate Professor of the Department of
Biomedical Disciplines, Belgorod State National Research University, E-mail: ponomarenko_i@ bsu.edu.ru, ORCID: 0000-0002-5652-0166

Статья поступила в редакцию 16 августа 2018 г. Receipt date 2018 August 16.

Статья принята к публикации 17 декабря 2018 г.

Accepted for publication 2018 December 17. 